\title{
THE
}

\section{Remote Sensing Applications in Monitoring of Protected Areas}

\author{
Yeqiao Wang \\ University of Rhode Island, yqwang@uri.edu
}

Zhong Lu

Yongwei Sheng

Yuyu Zhou

Follow this and additional works at: https://digitalcommons.uri.edu/nrs_facpubs

Creative Commons License

\section{(c) (†)}

This work is licensed under a Creative Commons Attribution 4.0 License.

\section{Citation/Publisher Attribution}

Wang, Y.; Lu, Z.; Sheng, Y.; Zhou, Y. Remote Sensing Applications in Monitoring of Protected Areas. Remote Sens. 2020, 12, 1370.

Available at: https://doi.org/10.3390/rs12091370

This Article is brought to you for free and open access by the Natural Resources Science at DigitalCommons@URI. It has been accepted for inclusion in Natural Resources Science Faculty Publications by an authorized administrator of DigitalCommons@URI. For more information, please contact digitalcommons-group@uri.edu. 


\title{
Remote Sensing Applications in Monitoring of Protected Areas
}

\author{
Yeqiao Wang ${ }^{1, *}$, Zhong Lu $^{2}$, Yongwei Sheng ${ }^{3}$ and Yuyu Zhou ${ }^{4}$ \\ 1 Department of Natural Resources Science, University of Rhode Island, Kingston, RI 02881, USA \\ 2 Huffington Department of Earth Sciences, Southern Methodist University, Dallas, TX 75275, USA; \\ zhonglu@smu.edu \\ 3 Department of Geography, University of California, Los Angeles (UCLA), Los Angeles, CA 90095, USA; \\ ysheng@geog.ucla.edu \\ 4 Department of Geological \& Atmospheric Sciences, Iowa State University, Ames, IA 50011, USA; \\ yuyuzhou@iastate.edu \\ * Correspondence: yqwang@uri.edu
}

Received: 21 April 2020; Accepted: 24 April 2020; Published: 26 April 2020

\begin{abstract}
Protected areas (PAs) have been established worldwide for achieving long-term goals in the conservation of nature with the associated ecosystem services and cultural values. Globally, $15 \%$ of the world's terrestrial lands and inland waters, excluding Antarctica, are designated as PAs. About $4.12 \%$ of the global ocean and $10.2 \%$ of coastal and marine areas under national jurisdiction are set as marine protected areas (MPAs). Protected lands and waters serve as the fundamental building blocks of virtually all national and international conservation strategies, supported by governments and international institutions. Some of the PAs are the only places that contain undisturbed landscape, seascape and ecosystems on the planet Earth. With intensified impacts from climate and environmental change, PAs have become more important to serve as indicators of ecosystem status and functions. Earth's remaining wilderness areas are becoming increasingly important buffers against changing conditions. The development of remote sensing platforms and sensors and the improvement in science and technology provide crucial support for the monitoring and management of PAs across the world. In this editorial paper, we reviewed research developments using state-of-the-art remote sensing technologies, discussed the challenges of remote sensing applications in the inventory, monitoring, management and governance of PAs and summarized the highlights of the articles published in this Special Issue.
\end{abstract}

Keywords: protected areas (PAs); biodiversity conservation; spatiotemporal dynamics; climate change; human disturbances; management and governance

\section{Introduction}

The World Commission on Protected Areas adopted a definition that describes a protected area (PA) as a clearly defined geographical space, recognized, dedicated and managed, through legal or other effective means, to achieve the long-term conservation of nature with the associated ecosystem services and cultural values [1]. In general, protected areas (PAs) include national parks (NPs), national forests, national seashores, all levels of natural reserves, wildlife refuges and sanctuaries, designated areas for the conservation of native biological diversity and natural and cultural heritage and significance. PAs also include some of the last frontiers that have unique landscape characteristics and ecosystem functions in wilderness conditions [2]. Along shorelines and over ocean and sea, the International Union for the Conservation of Nature (IUCN) has defined marine protected areas (MPAs) as any area of intertidal or subtidal terrain, together with its overlying water and associated flora, fauna, historical and cultural features, which has been reserved by law or other 
effective means to protect part or all of the enclosed environment [3]. As reported by the World Database on Protected Areas (WDPA, https://www.protectedplanet.net/), 15\% of the world's terrestrial lands and inland waters, excluding Antarctica, is under protection. About $4.12 \%$ of the global ocean and $10.2 \%$ of the coastal and marine areas under national jurisdiction are set as MPAs. About $19.2 \%$ of key biodiversity areas are completely covered as PAs [4]. Protected lands and waters serve as the fundamental building blocks of virtually all national and international conservation strategies, supported by governments and international institutions. These policies and their implementations provide the protection of threatened species around the world. The IUCN has categorized PAs into seven types, namely the strict nature reserve (Ia), wilderness area (Ib), national park (II), natural monument or feature (III), habitat/species management area (IV), protected landscape/seascape $(\mathrm{V})$ and the protected area with a sustainable use of natural resources (VI) [1]. PAs are increasingly recognized as essential providers of ecosystem services and biological resources, key components in climate change mitigation strategies, as well as vehicles for protecting threatened human communities or sites of great cultural and spiritual value.

PAs have been created over past millennia for a multitude of reasons [5]. The establishment of the Yellowstone National Park in 1872 by the United States (U.S.) Congress ushered in the modern era of the governmental protection of natural areas, which catalyzed a global movement $[6,7]$. The 1916 National Park Service Organic Act of the United States established the purpose of national parks, including to conserve the scenery and the natural and historic objects and the wild life therein, and to provide for the enjoyment of the same in such a manner and by such means that will leave them unimpaired for the enjoyment of future generations [8]. As the National Parks Omnibus Management Act of 1998, the agency undertook a program of inventory and monitoring of National Park System resources to establish the baseline information and to provide information on the long-term trends in the condition of National Park System resources [9]. Remote sensing applications have contributed greatly in such inventory and monitoring efforts [10-12].

Even with the implementation of a tremendous variety of monitoring programs and conservation efforts with achievements, wild species' population decline, biodiversity loss, extinction, system degradation, pathogen spread and state change events are occurring at unprecedented rates [13,14]. The effects are augmented by continued changes in land use, invasive spread, alongside the direct, indirect and interactive effects of climate change and disruption. PAs become more important in serving as indicators of ecosystem conditions and functions either by their status and/or by contrasting to their adjacent unprotected areas. PAs are highly prized by the society with diversified representative characteristics. Earth's remaining wilderness areas are becoming increasingly important buffers against the changing environmental conditions. However, they are not an explicit target in many international policy frameworks [15]. The most recent United Nation's report concluded that up to one million animal and plant species were facing extinction, for which humans were to blame [16]. The most impacting drivers on global biodiversity scenarios toward the year 2100 include human-induced changes in land use, climate, nitrogen deposition, biotic exchange and atmospheric $\mathrm{CO}_{2}[17]$.

The WDPA data showed that the Latin American and the Caribbean regions have 4.85 million $\mathrm{km}^{2}(24 \%)$ of protected land. Brazil has half $\left(2.47\right.$ million $\left.\mathrm{km}^{2}\right)$ of the entire region protected, making it the largest national terrestrial PA network in the world [WDPA, https://protectedplanet.net/]. Worldwide, $77 \%$ of land, excluding Antarctica, and $87 \%$ of the ocean has been modified by the direct effects of human activities [18]. PAs in China, for example, have typically incorporated core and buffer zones with human habitation. A study mapped and analyzed the human footprint index at 1$\mathrm{km}$ scale for 1834 terrestrial nature reserves of mainland China and concluded that the reserves designated at higher levels of governance were more pristine than those at lower levels. This was significant as China started to consider the reclassification of some reserves as NPs [19]. Another nationwide assessment quantified the provision of threatened species habitats and key regulating services in natural reserves in China. The study illuminated a strategy for strengthening PAs through creating the first comprehensive national park system of China [20]. As a strategic movement, in June 2019, the Chinese government announced a guideline for the establishment of a new NP-centered 
system for the protection of natural areas with the implementation plan in 2020. The crown jewels on the list of the first 10 designated NPs included the Three-River-Source NP, Giant Panda NP, Northeastern China Tiger and Leopard NP, among others. The Three-River-Source NP covers an area of about $363,000 \mathrm{~km}^{2}$ and encompasses the headwaters of three major rivers, i.e., the Yellow, Yangtze and Lancang rivers, in the eastern Tibetan Plateau. The comprehensive system of NPs aims to protect the lands and waters with key natural resources and biodiversity.

Remote sensing provides a comprehensive geospatial capacity to map and study PAs in different spatial details and contexts, e.g., pixel size, area coverage, immediate adjacent areas of PAs and the broader background of the land and water that support the PAs; temporal frequencies, e.g., daily, weekly and monthly observations; and spectral properties. Remote sensing observations, in combination with field-based measurements, create new and exciting opportunities to meet the needs of monitoring PAs [21].

\section{Remote Sensing Applications in Monitoring of Protected Areas}

It has long been recognized that the on-the-ground monitoring of PA ecosystems is expensive, primarily due to the size and logistical constraints of national parks, designated wilderness, wildlife refuges and other large PAs. Remote sensing monitoring can provide essential information for the efficient, transparent, repeatable and defensible decision making in ecological systems [22]. The integration of ground-based data (e.g., focal species populations) and remote sensing has been practiced in monitoring and modeling environmental change in many PAs [5,23-25].

Remote sensing has unique advantages in monitoring the landscape dynamics of PAs around the world. The temporal depth of remote sensing can be used to provide monitoring with the continuity of deployments of new satellites and sensor systems and image acquisition capability. Multispectral optical sensors, e.g., the Landsat Thematic Mapper (TM), Enhanced Thematic Mapper Plus (ETM+) and Operational Land Imager (OLI), Advanced Spaceborne Thermal Emission and Reflection Radiometer (ASTER), SPOT High Resolution Visible (HRV) and High Resolution Visible and Infrared (HRVIR), Moderate Resolution Imaging Spectroradiometer (MODIS), Visible Infrared Imaging Radiometer Suite (VIIRS), Advanced Very-High-Resolution Radiometer (AVHRR) and Sentinel-2 MultiSpectral Instrument (MSI), and the derivatives of data products, have been routinely applied in PA inventory and monitoring research and applications. The approaches translated an ecologically based view of change into the spectral domain when archives of multispectral images were considered. Spectral indices have been used as the proxy for ecological attributes and have been tracked as time-series trajectories. The developed algorithms use statistical fitting rules to identify periods of consistent progression in the spectral trajectory (segments) and the turning points (vertices) that separate these periods. The change detection methods capture a wide range of processes affecting vegetation, such as the decline and mortality, growth and recovery and the combination of other driving factors $[18,26,27]$. Active sensors, such as the synthetic aperture radar (SAR), and satellites including the European Remote Sensing (ERS-1/-2) and Envisat, the Japanese Earth Resources Satellite 1 (JERS-1), the Phased Array type L-band Synthetic Aperture Radar (PALSAR-1/-2), RADARSAT-1/-2, the Constellation of Small Satellites for Mediterranean Basin Observation (COSMO-SkyMed), TerraSAR-X and TanDEM-X, and Sentinel-1A/B, have been proven effective in monitoring the changing environments at the local, regional and global scales [28-33]. The interferometric synthetic aperture radar (InSAR) has been used to construct a global digital elevation model (DEM), to map characteristics of the Earth's surface and measure land surface deformation at an unprecedented precision and spatial resolution under all-weather conditions [34].

Time-series remote sensing data have allowed for the reconstruction of the histories of disturbances induced by anthropogenic and natural impacts. Typical examples have included: the inventory and monitoring studies in NPs and PAs in a landscape context, such as in the Acadia NP and other northeastern U.S. NPs [12,35], the Yellowstone NP [36] and the Olympic NP of the Pacific Northwest of the U.S. [37]; for monitoring the interannual variability in snowpack and lake ice in southwest Alaska [38]; in the assessment of national forests of eastern U.S. [39]; in monitoring the land cover change and ecological integrity of Canada's national parks [40], such as the wildlife habitat 
changes in Kejimkujik NP and the national historic site in southern Nova Scotia of the Canadian Atlantic Coastal Uplands Natural Region [41]; in operational active fire mapping and burnt area identification to Mexican nature PAs [42]; in Tibetan Plateau [43] and Changbai Mountain National Nature Reserve [44,45] of China.

Remote sensing has unique advantages in monitoring frontier lands, which are always in remote and difficult-to-reach locations. Examples have included: satellite-observed dynamics of lake-rich regions across the Tibetan Plateau and the Arctic; forest disturbance and dynamics in Siberia; the assessment of the complex Amur tiger and Far Eastern leopard habitats in the Russian Far East; in the landscape and ecosystem characterizations in China and Southeast Asia; in conservation efforts of tree kangaroos in Papua New Guinea; and in PAs in the Albertine Rift of Africa [46-62]. Remote sensing has advantages in monitoring vast habitats both inside and surrounding the PAs. This is particularly true when ecological functioning and habitats within NPs and PAs are influenced by natural resources outside of their borders [63-65]. Remote sensing applications have been among the critical approaches in the assessment of landscape contexts and the conversion risks of PAs surrounded by accelerated human population growth [66-70].

MPAs are among the critical components of protected waters. Important factors that affect the way plants and animals respond to MPAs include the distribution of habitat types, the level of connectivity to nearby fish habitats, wave exposure, depth distribution, prior level of resource extraction and regulations. Conservation benefits are evident through increased habitat heterogeneity at the seascape level, the increased abundance of threatened species and habitats and the maintenance of a full range of genotypes [71]. Remote sensing data that quantify spatial patterns in habitat type, oceanographic conditions, and benthic complexity can be integrated with in situ ecological data for the design, evaluation and the monitoring of MPA networks to design, assess and monitor MPAs [72,73]. Combining remote sensing products with in situ ecological and physical data can support the development of a statistically robust monitoring program of the living marine resources within and adjacent to marine protected areas [74]. Individual MPAs need to be networked in order to provide large-scale ecosystem benefits and to have the greatest chance of protecting all species, life stages and ecological linkages if they encompass representative portions of all ecologically relevant habitat types in a replicated manner. High-resolution remote sensing data are capable of mapping the physical and biological features of a benthic habitat, such as the monitoring of the coral reef in the Hawaii Archipelago and near-shore PAs in California and New England [75].

Coastal habitats, such as sand dunes, barrier islands, tidal wetlands, marshes, mangrove forests and submerged aquatic vegetation provide foods, shelters and breeding grounds for terrestrial and marine species. Coastal habitats also provide irreplaceable services such as filtering pollutants and retaining nutrients, maintaining water quality, protecting shorelines and absorbing flood waters. As coastal habitats are facing intensified natural and anthropogenic disturbances through direct impacts such as hurricanes, tsunamis, harmful algae blooms and cumulative and secondary impacts such as climate change, sea level rise, oil spill and urban development, the inventory and monitoring of coastal environments has become one of the most challenging tasks of the society in resource management and humanity administration. Remote sensing technologies with space-borne and airborne sensor systems in data acquisition and observation have profoundly changed the practice of monitoring and understanding the dynamics of coastal environments. Remote sensing applications have greatly enhanced the monitoring capacity of coastal PAs and practical implementations across spatial scales [76,77]. Very high resolution (VHR) imageries from airborne and satellite sensors, unmanned aerial vehicles (UAV), light detection and ranging (LiDAR), hyperspectral sensors, ground-based sensor networks and wireless geospatial service web systems have been increasingly applied with local focused interests on coastal PAs [78-86].

The improved capacity of data science and infrastructure, e.g., cloud computing, Google Earth Engine (GEE) and big Earth data approaches, facilitates data sharing and the integration and modeling processes [87-89]. For example, the capacity and service from GEE open opportunities for explorations that benefit from decades of data acquisition from remote sensing [90-96].

\section{Challenges of Remote Sensing Monitoring of Protected Areas}


The impacts of climate and human-induced environmental changes will continue to disrupt ecosystem functions and services, as well as the habitats and biodiversity. The future projections indicate a potentially catastrophic loss of global biodiversity [97-102]. Earth's remaining wilderness areas are becoming increasingly important buffers against changing conditions. Protected lands and waters are becoming more important, serving as indicators of ecosystem status and functions and as the barometer for guiding the national and international strategies in collaborated mitigation and conservation efforts.

PAs are functional from many forms of direct human intervention. The landscapes and seascapes of PAs are dynamic rather than static. Vegetation is changing continuously in response to both endogenous and exogenous pressures. PAs and their networks provide critical habitats for biodiversity conservation and yet their performances are challenged under the changing climate and shifting resource patterns [103]. Monitoring the dynamics of PAs requires tools that capture a wide range of processes over large areas. The evaluation of management effectiveness is a vital component of responsive, pro-active PA management [104,105]. Ecosystem indicators, whether process-based (e.g., productivity), pattern-based (e.g., land-use activities), or component-based (specie populations), vary in space and time. A major limiting factor in comprehensive ecological models is the lack of explanatory geospatial data. The issues conspire against the ready, standardized integration of remote sensing into ecological research for the management and governance of PAs.

Remote sensing is a universal tool for scientists and land managers. New developments of remote sensing platforms, sensors and improvements in science and technology provide crucial support for monitoring PAs across the world. Remote sensing data products, coupled with userfriendly data exploration, analyses, and accessible modeling tools, allow scientists and practitioners to gain a better understanding of how environmental changes affect specie populations, ecosystem functions and the services that sustain them. The lessons learned and the recommendations put forward for the remote sensing of PAs include: the allocation of sufficient time to develop a genuine science-management partnership; the communication of results in a management-relevant context; the confirmation or embellishment of existing frameworks and processes; plans for persistence and change; and to build on existing, widely used data analysis tools and software frameworks [10,21].

Field survey and in situ observations are essential to identify protected habitats through remote sensing. Almost every remote sensing exercise requires a field survey to define the habitats, to calibrate remote sensing imagery and to evaluate the accuracy out of remote sensing outputs [106]. With precise and accurate positioning and field survey becoming a routine operation, challenges remain for the incorporation of data from ground-based sensor networks and wireless geospatial service web systems with remote sensing observations for the comprehensive analyses and assessment of PAs.

The monitoring of landscape dynamics of PAs is among the primary advantage of remote sensing. The link between the pattern and the process, however, has been identified as a seminal challenge in landscape ecology. Disturbance is an important process that creates and responds to a pattern. The integration of remote sensing-based and in situ monitoring, including the consideration of scaling site observations, to the ecosystem level and the explicit link through ecosystem-based modeling to management options and recommendations, present the practical challenges and opportunities in the variety of PAs [23,26,39].

Remote sensing science is effective for managers and researchers across many domains. The lack of standardized protocols, workflow architecture, guidelines, training and software tools has led into a complexity. When evaluating the trends in resource and ecological conditions, the resource managers of PAs pursue analyses that use all the available information. Thus, they seek remote sensing change detection analyses that may include historical aerial photography, combined with more recent satellite images acquired in different spectral bands at various spatial and temporal resolutions. In addition, many resource problems must be evaluated at multiple spatial scales $[12,69]$. These practical issues result in unusually complex requirements and procedures that can be worked out only through the sustained collaboration between remote sensing scientists and PA managers. A key lesson is about the importance, difficulty and time-consumption of the mutual learning process 
[11]. In the management perspectives, there is a considerable potential to expand the operational use of remote sensing to monitor PAs among routine implementations. The uses of such information in operational monitoring present difficulties in designing and implementing a program that provides useful information at management levels and at an affordable cost $[18,107]$. The integration of remote sensing data into a framework for the data assimilation, processing, modeling and reporting is becoming essential [108-110].

It is worthy to point out that one of the most important limitations to the use of remote sensing data for the monitoring of PAs is the variant mapping accuracy and the cost of acquiring groundbased data for verification and validation. This is a common challenge of obtaining and integrating traditional in situ measurements and approaches with remote sensing mapping and modeling. It also shows that remote sensing cannot always meet the entire information collection needs. Whereas remote sensing-based techniques address spatial and temporal domains inaccessible to traditional approaches, remote sensing cannot match the accuracy, precision and the thematic richness of in situ measurements and monitoring at the plot scale. Therefore, the design of remote sensing-based monitoring methods needs to be carefully integrated with a very efficient protocol for the inclusion of field observations and survey data $[10,111]$.

As the amenity values of PAs attract the rapid developments and impacts of human-induced land use change, remote sensing has to meet an increasingly essential requirement to address a range of monitoring across spatial scales and from terrestrial to coastal and open waters [112-113]. Challenges and uncertainties remain for the data continuity and systematic technology improvements toward consistent long-term monitoring applications in the future [114].

\section{Highlights of the Special Issue Articles}

With the rapid development of remote sensing science and technologies, this Special Issue aims to publish original manuscripts of the latest innovative research and advancement in the remote sensing of PAs. The articles in this Special Issue include applications of using data from multiple sensor systems in the monitoring of PAs from global to local interests.

The Defense Meteorological Satellite Program/Operational Linescan System (DMSP/OLS) nighttime stable light (NTL) has been proven to be an effective indicator of the intensity and change of human-induced urban development over a long time span and at a larger spatial scale [115]. The study by Fan et al. [116] used the NTL data from 1992 to 2013 to characterize the human-induced urban development and studied the spatial and temporal variation of the NTL of global terrestrial PAs. The study selected seven types of PAs defined by the IUCN, including the strict nature reserve (Ia), the wilderness area (Ib), the national park (II), the natural monument or feature (III), the habitat/species management area (IV), the protected landscape/seascape (V), and the protected area with a sustainable use of natural resources (VI). The study evaluated the NTL magnitudes in PAs and their surrounding buffer zones. The results revealed the level, growth rate, trend and distribution pattern of the NTL in global PAs.

Terrestrial biophysical variables play an essential role in quantifying the amount of energy budget, water cycle and carbon sink over the Three-River Headwaters Region of China (TRHR). Bei et al. [117] evaluated the spatiotemporal dynamics of the biophysical variables including meteorological variables, vegetation and evapotranspiration (ET) over the TRHR and analyzed the response of the vegetation and the ET to climate change in the period from 1982 to 2015 using the China Meteorological Forcing Dataset (CMFD) and the Global Inventory Modeling and Mapping Studies (GIMMS) NDVI3g product, among others. The main input gridded datasets included meteorological reanalysis data, a satellite-based vegetation index dataset and the ET product developed by a process-based Priestley-Taylor algorithm. The study suggested a 'dryer warming' and a 'wetter warming' tendency in different areas of the TRHR. The study revealed that more than $56.8 \%$ of the areas in the TRHR presented a significant increment in vegetation. The analysis noted that the ET was governed by the terrestrial water supply in the arid region of the western TRHR.

Salt marshes are changing due to natural and anthropogenic stressors such as sea level rise, nutrient enrichment, herbivory, storm surge and coastal development. A study by Campbell and 
Wang [105] analyzed the salt marsh change at the Fire Island National Seashore, a nationally protected area in New York, using the object-based image analysis (OBIA) to classify a combination of data from Worldview-2 and Worldview-3 satellites, Topobathymetric LiDAR, and National Agricultural Imagery Program (NAIP) aerial imageries. The salt marsh classification was trained and tested with the vegetation plot data. In October 2012, Hurricane Sandy caused extensive overwash and breached a section of the island. This study quantified the continuing effects of the breach on the surrounding salt marsh. The tidal inundation at the time of image acquisition was analyzed using the LiDAR-derived DEM to create a bathtub model at the target tidal stage. The study revealed the geospatial distribution and rates of change within the salt marsh interior and the salt marsh edge. The Worldview imagery was able to classify the salt marsh environments accurately at an overall accuracy of $92.75 \%$. The study suggested that the NAIP data were adequate for determining the rates of salt marsh change with a high accuracy. The cost and revisit time of the NAIP imagery created an ideal open data source for high spatial resolution monitoring and the change analysis of salt marsh environments.

Anticipating how boreal forest landscapes will change in response to fire regimes requires disentangling the effects of various spatial controls on the recovery process of tree saplings. The spatially explicit monitoring of post-fire vegetation recovery through moderate resolution Landsat imagery is a popular technique but is filled with ambiguous information due to mixed pixel effects. On the other hand, very-high resolution satellite imagery accurately measures the crown size of tree saplings but has gained little attention. Its utility for estimating leaf area index (LAI) and tree sapling abundance (TSA) in post-fire landscapes remains untested. A study by Fang et al. [118] compared the explanatory power of the Landsat imagery with $0.5-\mathrm{m}$ WorldView-2 VHR imagery for the LAI and TSA based on the field-sampling data and subsequently mapped the distribution of the LAI and TSA based on the most predictive relationships. The results showed that the pixel percentage of the canopy trees (PPCT) derived from VHR imagery outperformed all the Landsat-derived spectral indices for explaining the variance of the LAI and TSA. The analyses concluded that mitigating wildfire severity and size may increase forest resilience to wildfire damage. Given the easily damaged seed banks and relatively short seed dispersal distance of coniferous trees, reasonable human help for the natural recovery of coniferous forests was necessary for severe burns with a large patch size, particularly in certain areas. The research showed that WorldView-2 VHR imagery better resolved the key characteristics of forest landscapes, providing a valuable tool to land managers and researchers alike.

Climate change and human activities alter the spatial distribution and structure of vegetation, especially in drylands. In this context, the object-based image analysis (OBIA) has been used to monitor changes in vegetation, but only a few studies have related them to anthropogenic pressure. Guirado et al. [119] assessed changes in the cover, number and shape of Ziziphus lotus shrub individuals in a coastal groundwater-dependent ecosystem in Spain over a period of 60 years and related them to human activities in the area. In particular, the study evaluated how sand mining, groundwater extraction and the protection of the area affected the shrubs. To do this, the study developed an object-based methodology to create accurate maps of the vegetation patches and compared the cover changes in the individuals. The changes in shrub size and shape were related to soil loss, seawater intrusion and the legal protection of the area measured by the average minimum distance and average random distance analysis. It was found that both the sand mining and seawater intrusion had a negative effect on individuals; on the contrary, the protection of the area had a positive effect on the size of the individuals' coverage. The findings supported the use of the OBIA for monitoring scattered vegetation patches in drylands, key to any monitoring program aimed at vegetation preservation.

Forest condition is the baseline information for ecological evaluation and management. A study by Chen et al. [120] mapped the structure and function parameters for forest condition assessment in the Changbai Mountain National Nature Reserve (CMNNR). Various mapping algorithms, including statistical regression, random forests, and random forest kriging were employed with predictors from Advanced Land Observing Satellite (ALOS)-2, Sentinel-1, Sentinel-2 satellite sensors, digital surface 
model of ALOS and 1803 field-sampled forest plots. The combined predicted parameters and weights from the principal component analysis as well as the forest conditions were assessed. The models explained the spatial dynamics and characteristics of forest parameters based on the independent validation. The mean assessment score suggested that forest conditions in the CMNNR were mainly the result of spatial variations of function parameters such as stand volume and soil fertility. This study provided a methodology on forest condition assessment at regional scales, as well as the upto-date information for the forest ecosystem in the CMNNR.

Han et al. [121] reported on the monitoring of droughts in the Greater Changbai Mountains (GCM) region by six drought indices, i.e., the precipitation condition index (PCI), temperature condition index (TCI), vegetation condition index (VCI), vegetation health index (VHI), scaled drought condition index (SDCI) and the temperature-vegetation dryness index (TVDI), between 2001 and 2018. This study provided a reference for the selection of drought indices for monitoring droughts to gain a better understanding of the ecosystem conditions and the environment.

The Songnen Plain (SNP) is an important grain production base and a designated red-line protection in China. The understanding of carbon use efficiency (CUE) of natural ecosystems in protected farmland areas is vital to predicting the impacts of natural and anthropogenic disturbances on carbon budgets and evaluating ecosystem functions. An article by Li et al. [122] studied variations in the ecosystem CUE in the SNP using MODIS data products and the Carnegie-Ames-Stanford approach (CASA) model. The relationships revealed between the CUE and the phenological and climate factors helped explain the CUE of the natural ecosystems in the protected farmland areas and improved the understanding about the dynamics of ecosystem carbon allocation in temperate semihumid to semi-arid transitional regions under climate and phenological fluctuations.

The comparative evaluation of cross-boundary wetland PAs is essential to underpin knowledgebased bilateral conservation policies and funding decisions by governments and managers. The article by Lu et al. [123] reported on a study of monitoring wetland change in the Wusuli River Basin in the crossboundary zone of China and Russia from 1990 to 2015 using Landsat images. The spatialtemporal distribution of wetlands was identified using a rule-based object-oriented classification method. The wetland dynamics were determined by combining the annual land change area (ALCA), the annual land change rate (ALCR), the landscape metrics and the spatial analysis. The study revealed the changes of the natural wetlands in the Wusuli River Basin and the patterns of change. The study provided critical information for the conservation and management of ecological conditions in cross-boundary wetlands.

Despite recent progress in landslide susceptibility mapping, a holistic method is still needed to integrate and customize influential factors with a focus on forest regions. A study by Shirvani [124] tested the performance of geographic object-based random forest modeling in the susceptibility of protected and non-protected forests to landslides in northeast Iran using Landsat 8 multispectral images and DEM data. The study derived features of conditioning factors. The study confirmed that some anthropogenic activities such as forest fragmentation and logging significantly intensified the susceptibility of the non-protected forests to landslides.

As the largest freshwater lake in China, Poyang Lake provides tremendous services and functions to its surrounding ecosystem, such as water conservation and the sustaining of biodiversity, and has significant impacts on the security and sustainability of the regional ecology. The lake and associated wetlands are among the protected aquatic ecosystems with global significance. The Poyang Lake region has recently experienced increased urbanization and anthropogenic disturbances, which has greatly impacted the lake environment. The concentrations of chlorophyll-a (Chl-a) and total suspended matter (TSM) are important indicators for assessing the water quality of lakes. The study by Xu et al. [125] used data from the Gaofen-1 (GF-1) satellite, in situ measurements of the reflectance of the lake water and the analysis of the Chl-a and TSM concentrations of the lake water samples to investigate the spatial and temporal variation and distribution patterns. The study analyzed the measured reflectance spectra and conducted a correlation analysis to identify the spectral bands that were sensitive to the concentration of Chl-a and TSM, respectively. The modeling 
results revealed the spatial and temporal variations of the water quality in Poyang Lake and demonstrated the capacities of the GF-1 satellite data in the monitoring of lake water quality.

The article by Duan et al. [126] presented an analysis of research publications, from a bibliometric perspective, on the remote sensing of PAs. The analysis focused on the time period from 1991 to 2018. The study extracted 4546 academic publications from the Web of Science database. Using VOSviewer software, the study evaluated the co-authorships among countries and institutions, as well as the co-occurrences of the keywords. The results indicated an increasing trend of annual publications in the remote sensing of PAs. This analysis revealed the major topical subjects, leading countries and most influential institutions around the world that have conducted relevant research in scientific publications. The study also revealed the journals that published the most articles in the subject of interests and the collaborative patterns related to the remote sensing of PAs. The analysis provided insights for understanding the intellectual structure of the field and identifying the future research directions.

\section{Conclusion Remarks}

Remote sensing is among the most fascinating frontiers of science and technology that are constantly improving our understanding of PAs. PAs are by no means uniform entities and have a wide range of management aims and are governed by many stakeholders. Advances in remote sensing have helped gather and share information about PAs at unprecedented rates and scales. There are many new and exciting applications for remotely sensed data that contribute to the better informing management of PAs. The achievements through the applications of science and technologies, the challenges, the lessons learned and the recommendations for the remote sensing of PAs deserve further attention [127].

The subjects and contents of the articles collected in this Special Issue reflect the state-of-the-art of remote sensing technologies for: capturing the dynamics of ecosystem variations; the evaluations of available sensors, data and the new development of integrated approaches; the methods for processing advanced remote sensing and time series data; and the integration of multisource and open source data. These studies contributed in the monitoring of PAs from the perspectives of in situ measurements, habitat assessments, socio-economic development, policy and management factors, and in inventory and practical implementations. The applications of monitoring from biospheric, atmospheric, hydrospheric and societal dimensions reflect the advantages of remote sensing in habitat mapping and biodiversity conservation, in the detection of effects from natural and anthropogenic disturbances, as well as in revealing uncertainties for the assessment of the resilience and sustainability of PAs and the mitigation approaches under the changing environments.

Acknowledgments: As the Guest Editors, we appreciate the professionalism and support from all contributors, editors, and reviewers for their efforts and dedication toward the advancement of remote sensing in monitoring of protected areas with the publication of this Special Issue.

Conflicts of Interest: The authors declare no conflict of interest.

\section{References}

1. Dudley, N. Guidelines for Applying Protected Area Management Categories; IUCN: Gland, Switzerland, 2008.

2. Wang, Y. Remote Sensing of Protected Lands; CRC Press: Boca Raton, FL, USA, 2011; ISBN 978-1-4398-4187-7.

3. Kelleher, G. Guidelines for Marine Protected Areas; IUCN: Gland, Switzerland, 1999.

4. UNEP-WCMC and IUCN. Protected Planet Report 2016; UNEP-WCMC: Cambridge, UK; IUCN: Gland, Switzerland, 2016.

5. Crabtree, R.; Sheldon, J. Monitoring and modeling environmental change in protected areas: Integration of focal species populations and remote sensing. In Remote Sensing of Protected Lands; CRC Press: Boca Raton, FL, USA, 2011; pp. 495-524.

6. IUCN. Shaping a sustainable future. In The IUCN Programme 2009-2012; IUCN: Gland, Switzerland, 2008.

7. Heinen, J.; Hite, K. Protected natural areas. In Encyclopedia of Earth; Cutler, J., Cleveland. C.J., Ed.; Environmental Information Coalition, National Council for Science and the Environment: Washington, DC, USA, 2007. 
8. National Park Service. Organic Act of 1916. Available online: https://www.nps.gov/grba/learn/management/organic-act-of-1916.htm (accessed on 20 April 2020).

9. National Park Service. National Parks Omnibus Management Act of 1998. Available online: https://www.nps.gov/gis/data_standards/omnibus_management_act.html (accessed 20 April 2020).

10. Gross, J.E.; Goetz, S.J.; Cihlar, J. Application of remote sensing to parks and protected area monitoring: Introduction to the special issue. Remote Sens. Environ. 2009, 113, 1343-1345.

11. Kennedy, R.E.; Townsend, P.A.; Gross, J.E.; Cohen, W.B.; Bolstad, P.; Wang, Y.Q.; Adams, P. Remote sensing change detection and natural resource monitoring for managing natural landscapes. Remote Sens. Environ. 2009, 113, 1382-1396.

12. Wang, Y.; Mitchell, B.R.; Nugranad-Marzilli, J.; Bonynge, G.; Zhou, Y.; Shriver, G.W. Remote sensing of land-cover change and landscape context of the national parks: A case study of the Northeast Temperate Network. Remote Sens. Environ. 2009, 113, 1453-1461.

13. Hoffmann, M.; Hilton-Taylor, C.; Angulo, A.; Böhm, M.; Brooks, T.M.; Butchart, S.H.; Carpenter, K.E.; Chanson, J.; Collen, B.; Cox, N.A.; et al. The impact of conservation on the status of the World's vertebrates. Science 2010, 330, 1503-1509.

14. Pereira, H.M.; Leadley, P.W.; Proença, V.; Alkemade, R.; Scharlemann, J.P.; Fernandez-Manjarrés, J.F.; Araújo, M.B.; Balvanera, P.; Biggs, R.; Cheung, W.W.; et al. Scenarios for global biodiversity in the 21st century. Science 2010, 330, 1496-1501.

15. Watson, J.E.M.; Allan, J.R. Protected the Last of the Wild. Nature 2018, 563, 27.

16. IPBES. Intergovernmental Science-Policy Platform on Biodiversity and Ecosystem Services (IPBES) Media Release, Nature's Dangerous Decline 'Unprecedented' Species Extinction Rates 'Accelerating'; IPBES: Bonn, Germany, 2019.

17. Sala, O.E.F.S.; Chapin, J.J., III; Armesto, E.; Berlow, J.; Bloomfield, R.; Dirzo, E. Huber-Sanwald, L.F.; Huenneke, R.B.; Jackson, A.; Kinzig, R.; et al. Global Biodiversity Scenarios for the Year 2100. Science 2010, 287, 1770-1774.

18. Kennedy, R.E.; Yang, Z.; Cohen, W.B. Detecting trends in forest disturbance and recovery using yearly Landsat time series: 1. LandTrendr-Temporal segmentation algorithms. Remote Sens. Environ. 2010, 114, 2897-2910.

19. Buckley, R.; Zhou, R.; Zhong, L. How Pristine Are China 's Parks? Front. Ecol. Evol. 2016, 4, 136.

20. Xu, W.; Xiao, Y.; Zhang, J.; Yang, W.; Zhang, L.; Hull, W.; Wang, Z.; Zheng, H.; Liu, J.; Polasky, S.; et al. Strengthening protected areas for biodiversity and ecosystem services in China. PNAS 2017, 114, 16011606.

21. Fancy, S.G.; Gross, J.E.; Carter, S.L. Monitoring the condition of natural resources in U.S. National Parks. Environ. Monit. Assess. 2009, 151, 161-174.

22. Gross, J.E.; Nemani, R.R.; Turner, W.; Melton, F. Remote sensing for the national parks. Park Sci. 2006, 24, 30-36.

23. Nagler, P.L.; Glenn, E.P.; Hinojosa-Huerta, O. Synthesis of ground and remote sensing data for monitoring ecosystem functions in the Colorado River Delta, Mexico. Remote Sens. Environ. 2009, 113, 1473-1485.

24. Clark, J.; Wang, Y.; August, P. Assessing current and projected suitable habitats for tree-of-heaven along the Appalachian Trail, Philos. Trans. R. Soc. B 2012, 369, 20130192.

25. Fu, B.; Li, Y.; Wang, Y.; Campbell, A.; Zhang, B.; Yin, S.; Zhu, H.; Xing, Z.; Jin, X. Evaluation of riparian condition of Songhua River by integration of remote sensing and field measurements, Sci. Rep. 2017, 7, 2565.

26. Dennison, P.E.; Nagler, P.L.; Hultine, K.R.; Glenn, E.P.; Ehleringer, J.R. Remote monitoring of tamarisk defoliation and evapotranspiration following saltcedar leaf beetle attack. Remote Sens. Environ. 2009, 113, 1462-1472.

27. Wang, Y.; Moskovits, D.K. Tracking Fragmentation of Natural Communities and Changes in Land Cover: Applications of Landsat Data for Conservation in an Urban Landscape (Chicago Wilderness). Conserv. Biol. 2001, 15, 835-843.

28. Sippel, S.; Hamilton, S.; Melack, J. Inundation area and morphometry of lakes on the Amazon river floodplain, Brazil. Arch. Fur Hydrobiol. Stuttg. 1992, 123, 385-400.

29. Birkett, C. Synergistic remote sensing of Lake Chad: Variability of basin inundation. Remote Sens. Environ. 2000, 72, 218-236. 
30. Zhang, J.; Xu, K.; Yang, Y.; Qi, L.; Hayashi, S.; Watanabe, M. Measuring water storage fluctuations in lake Dongting, China, by topex/poseidon satellite altimetry. Environ. Monit. Assess. 2006, 115, 23-37.

31. Schlaffer, S.; Matgen, P.; Hollaus, M.; Wagner, W. Flood detection from multi-temporal SAR data using harmonic analysis and change detection. Int. J. Appl. Earth Obs. Geoinf. 2015, 38, 15-24.

32. Smith, L.C.; Sheng, Y.; MacDonald, G.M. A first pan-arctic assessment of the influence of glaciation, permafrost, topography and peatlands on northern hemisphere lake distribution. Permafr. Periglac. Process. 2007, 18, 201-208.

33. Matta, E.; Giardino, C.; Boggero, A.; Bresciani, M. Use of satellite and in situ reflectance data for lake water color characterization in the Everest Himalayan region. Mt. Res. Dev. 2017, 37, 16-23.

34. Lu, Z.; Zhang, L. Frontiers of Radar Remote Sensing: Photogram. Eng. Remote Sens. 2014, 80, 5-13.

35. Goetz, S.J.; Jantz, P.; Jantz, C.A. Connectivity of core habitat in the northeastern United States: Parks and protected areas in a landscape context. Remote Sens. Environ. 2009, 113, 1421-1429.

36. Crabtree, R.L.; Potter, C.S.; Mullen, R.S.; Sheldon, J.W.; Huang, S.; Harmsen, J.A. A modeling and spatiotemporal analysis framework for monitoring environmentalchange using NPP as an ecosystem indicator. Remote Sens. Environ. 2009, 113, 1486-1496.

37. Huang, C.; Schleerweis, K.; Thomas, N.; Goward, S.N. Forest Dynamics within and around Olympic National Park Assessed Using Time Series Landsat Observations. In Remote Sensing of Protected Lands; CRC Press: Boca Raton, FL, USA, 2011; pp. 75-94.

38. Reed, B.; Budde, M.; Spencer, P.; Miller, A.E. Integration of MODIS-derived metrics to assess interannual variability in snowpack, lake ice, and NDVI in southwest Alaska. Remote Sens. Environ. 2009, 113, 14431452.

39. Huang, C.; Goward, S.N.; Schleeweis, K.; Thomas, N.; Masek, J.G.; Zhu, Z. Dynamics of national forests assessed using the Landsat record: Case studies in eastern United States. Remote Sens. Environ. 2009, 113, 1430-1442.

40. Fraser, R.; Olthof, I.; Pouliot, D. Monitoring land cover change and ecological integrity in Canada's national parks. Remote Sens. Environ. 2009, 113, 1397-1409.

41. Zorn, P.; Ure, D.; Sharma, R.; O’ Grady, S. Using earth observation to monitor species-specific habitat change in the Greater Kejimkujik National Park Region of Canada. In Remote Sensing of Protected Lands; CRC Press: Boca Raton, FL, USA, 2011; pp. 95-110.

42. Ressl, R.; Lopez, G.; Cruz, I.; Ressl, S.; Schmidt, M.I.; Jiménez, R. Operational active fire mapping and burnt area identification applicable to Mexican nature protection areas using MODIS-DB data. Remote Sens. Environ. 2009, 113, 1113-1126.

43. Gillespie, T.W.; Madson, A.; Cusack, C.F.; Xue, Y. Changes in NDVI and human population in protected areas on the Tibetan Plateau, Arct. Antarct. Alp. Res. 2019, 51, 428-439.

44. Guo, X.; Zhang, H.; Wang, Y.; Clark, J. Mapping and assessing typhoon-induced forest disturbance in Changbai Mountain National Nature Reserve using time series Landsat imagery. J. Mt. Sci. 2015, 12, $404-$ 416.

45. Chi, H.; Sun, G.; Huang, J.; Li, R.; Ren, X.; Ni, W.; Fu, A. Estimation of Forest Aboveground Biomass in Changbai Mountain Region Using ICESat/GLAS and Landsat/TM Data. Remote Sens. 2017, 9, 707.

46. Sheng, Y.; Alsdorf, D. Automated ortho-rectification of Amazon basin-wide SAR mosaics using SRTM DEM data. IEEE Trans. Geosci. Remote Sens. 2005, 43, 1929-1940.

47. Arima, E.Y.; Walker, R.T.; Sales, M.; Souza, C., Jr.; Perz, S.G. The fragmentation of space in the Amazon basin: Emergent road networks. Photogram. Eng. Remote Sens. 2008, 74, 699-709.

48. Walsh, S.J.; Messina, J.P.; Brown, D.G. Mapping \& modeling land use/land cover dynamics in frontier settings. Photogram. Eng. Remote Sens. 2008, 74, 677-679.

49. Mena, C.F. Trajectories of land-use and land-cover in the northern Ecuadorian Amazon: Temporal composition, spatial configuration, and probability of change. Photogram. Eng. Remote Sens. 2008, 74, 737751.

50. Wang, C.; Qi, J.; Cochrane, M. Assessment of tropical forest degradation with canopy fractional cover from Landsat ETM+ and IKONOS imagery. Earth Interact. 2005, 9, 1-18.

51. Wang, C.; Qi, J. Biophysical estimation in tropical forests using JERS-1 SAR and VNIR Imagery: IIaboveground woody biomass. Int. J. Remote Sens. 2008, 29, 6827-6849.

52. Sun, G.; Ranson, K.J.; Kharuk, V.I. Radiometric slope correction for forest biomass estimation from SAR data in Western Sayani mountains, Siberia. Remote Sens. Environ. 2002, 79, 279-287. 
53. Bergen, K.M.; Zhao, T.; Kharuk, V.; Blam, Y.; Brown, D.G.; Peterson, L.K.; Miller, N. Changing regimes: Forested land cover dynamics in central Siberia 1974-2001. Photogram. Eng. Remote Sens. 2008, 74, 787-798.

54. Kharuk, V.I.; Ranson, K.J.; Im, S.T. Siberian silkmoth outbreak pattern analysis based on SPOT VEGETATION data. Int. J. Remote Sens. 2009, 30, 2377-2388.

55. Stow, D.A.; Hope, A.; McGuire, D.; Verbyla, D.; Gamon, J.; Huemmrich, F.; Houston, S.; Racine, C.; Sturm, M.; Tape, K.; et al. Remote sensing of vegetation and land-cover change in Arctic tundra ecosystems. Remote Sens. Environ. 2004, 89, 281-308.

56. Sheng, Y.; Shah, C.A.; Smith, L.C. Automated image registration for hydrologic change detection in the lake-rich arctic. IEEE Geosci. Remote Sens. Lett. 2008, 5, 414-418.

57. Sheng, Y.; Li, J. Satellite-observed endorheic lake dynamics across the Tibetan plateau between circa 1976 and 2000. In Remote Sensing of Protected Lands; CRC Press: Boca Raton, FL, USA, 2011; pp. 305-319.

58. Ranson, K.J.; Sun, G.; Kharuk, V.I.; Howl, J. Multisensor Remote Sensing of Forest Dynamics in Central Siberia. In Remote Sensing of Protected Lands; CRC Press: Boca Raton, FL, USA, 2011; pp. 321-377.

59. Sherman, N.J.; Loboda, T.V.; Sun, G.; Shugart, H.H. Remote sensing and modeling for assessment of complex Amur (Siberian) Tiger and Amur (Far Eastern) Leopard Habitats in the Russian Far East. In Remote Sensing of Protected Lands; CRC Press: Boca Raton, FL, USA, 2011, pp. 379-407.

60. Chen, L.; Ren, C.; Li, L.; Wang, Y.; Zhang, B.; Wang, Z.; Li, L. A Comparative Assessment of Geostatistical, Machine Learning, and Hybrid Approaches for Mapping Topsoil Organic Carbon Content. ISPRS Int. J. Geo-Inf. 2019, 8, 174.

61. Stabach, J.A.; Dabek, L.; Jensen, R.; Wang, Y.Q. Discrimination of dominant forest types for Matschie's tree kangaroo conservation in Papua New Guinea using high-resolution remote sensing data. Int. J. Remote Sens. 2009, 30, 405-422.

62. Ayebare, S.; Moyer, D.; Plumptre, A.J.; Wang, Y. Remote sensing for biodiversity conservation of the Albertine Rift in Eastern Africa. In Remote Sensing of Protected Lands; CRC Press: Boca Raton, FL, USA, 2011; pp. 183-201.

63. GAO (U.S. General Accounting Office). Activities Outside Park Borders Have Caused Damage to Resources and Will Likely Cause More; U.S. Government Printing Office GAO/RCED-94-59; GAO: Washington, DC, USA, 1994.

64. Hansen, A.J.; DeFries, R. Ecological mechanisms linking protected areas to surrounding lands. Ecol. Appl. 2007, 17, 974-988.

65. Svancara, L.; Scott, J.M.; Loveland, T.R.; Pidgorma, A.B. Assessing the landscape context and conversion risk of protected areas using remote-sensing derived data. Remote Sens. Environ. 2009, 113, 1357-1369.

66. Wittemyer, G.; Elsen, P.; Bean,W.T.; Burton, A.C.O.; Brashares, J.S. Accelerated human population growth at protected area edges. Science 2008, 321, 123-126.

67. Townsend, P.A.; Lookingbill, T.R.; Kingdon, C.C. Spatial pattern analysis for monitoring protected areas. Remote Sens. Environ. 2009, 113, 1410-1420.

68. Wiens, J.A.; Sutter, R.D.; Anderson, M.; Blanchard, J.; Barnett, A.; Aguilar-Amuchastegui, N. Selecting and conserving lands for biodiversity: The role of remote sensing. Remote Sens. Environ. 2009, 113, 1370-1381.

69. Jones, D.A.; Hansen, A.J.; Bly, K.; Doherty, K.; Verschuyl, J.P.; Paugh, J.I.; Carle, R.; Story, S.J. Monitoring land use and cover around parks: A conceptual approach. Remote Sens. Environ. 2009, 113, 1346-1356.

70. Lu, X.; Zhou, Y.; Liu, Y.; Yannick, L.P. The role of protected areas in land use/land cover change and the carbon cycle in the conterminous United States. Glob. Chang. Biol. 2017, doi:10.1111/gcb.13816.

71. Edgar, G.J.; Russ, G.R.; Babcock, R.C. Marine protected areas. In Marine Ecology; Oxford University Press: Oxford, UK, 2007; pp. 533-555.

72. Wedding, L.; Friedlander, A.M. Determining the influence of seascape structure on coral reef fishes in Hawaii using a geospatial approach. Mar. Geod. 2008, 31, 246-266.

73. Wedding, L.; Friedlander, A.; McGranaghan, M.; Yost, R.; Monaco, M.E. Using bathymetric Lidar to define nearshore benthic habitat complexity: Implications for management of reef fish assemblages in Hawaii. Remote Sens. Environ. 2008, 112, 4159-4165.

74. Friedlander, A.M.; Brown, E.K.; Monaco, M.E. Coupling ecology and GIS to evaluate efficacy of màine protected areas in Hawaii. Ecol. Appl. 2007, 17, 715-730.

75. Friedlander, A.M.; Wedding, L.M.; Caselle, J.E.; Costa, B.M. Integration of remote sensing and in situ ecology for the design and evaluation of marine protected areas: Examples from tropical and temperate ecosystems. In Remote Sensing of Protected Lands; CRC Press: Boca Raton, FL, USA, 2011; pp. 245-280. 
76. Wang, Y.; Tobey, J.; Bonynge, G.; Nugranad, J.; Makota, V.; Ngusaru, N.; Traber, M. Involving Geospatial Information in the Analysis of Land Cover Change along Tanzania Coast. Coast. Manag. 2005, 33, 89-101.

77. Wang, Y.; Traber, M.; Milestead, B.; Stevens, S. Terrestrial and submerged aquatic vegetation mapping in Fire Island National Seashore using high spatial resolution remote sensing data. Mar. Geod. 2007, 30, 77-95.

78. Li, X.; Cheng, X.; Gong, P.; Yan, K. Design and Implementation of a Wireless Sensor Network-Based Remote Water-Level Monitoring System. Sensors 2011, 11, 1706-1720.

79. Laliberte, A.S.; Goforth, M.A.; Steele, C.M.; Rango, A. Multispectral Remote Sensing from Unmanned Aircraft: Image Processing Workflows and Applications for Rangeland Environments. Remote Sens. 2011, 3, 2529-2551.

80. D’ Oleire-Oltmanns, S.; Marzolff, I.; Peter, K.D.; Ries, J.B. Unmanned Aerial Vehicle (UAV) for Monitoring Soil Erosion in Morocco. Remote Sens. 2012, 4, 3390-3416.

81. Hruska, R.; Mitchell, J.; Anderson, M.; Glenn, N.F. Radiometric and Geometric Analysis of Hyperspectral Imagery Acquired from an Unmanned Aerial Vehicle. Remote Sens. 2012, 4, 2736-2752.

82. Harwin, S.; Lucieer, A. Assessing the Accuracy of Georeferenced Point Clouds Produced via Multi-View Stereopsis from Unmanned Aerial Vehicle (UAV) Imagery. Remote Sens. 2012, 4, 1573-1599.

83. Wallace, L.; Lucieer, A.; Watson, C.; Turner, D. Development of a UAV-LiDAR System with Application to Forest Inventory. Remote Sens. 2012, 4, 1519-1543.

84. Campbell, A.; Wang, Y. Examining the Influence of Tidal Stage on Salt Marsh Mapping using High Spatial Resolution Satellite Remote Sensing and Topobathymetric LiDAR, IEEE Trans. Geosci. Remote Sens. 2018, 56, 5169-5176.

85. Campbell, A.; Wang, Y. Assessment of salt marsh change on Assateague Island National Seashore between 1962 and 2016. Photogram. Eng. Remote Sens. 2020, 86, 187-194.

86. Campbell, A.; Wang, Y.; Christiano, M.; Stevens, S. Salt Marsh Monitoring in Jamaica Bay, New York from 2003 to 2013: A Decade of Change from Restoration to Hurricane Sandy. Remote Sens. 2017, 9, 131.

87. Hansen, M.C.; Potapov, P.V.; Moore, R.; Hancher, M.; Turubanova, S.A.; Tyukavina, A.; Thau, D.; Stehman, S.V.; Goetz, S.J.; Loveland, T.R.; et al. High-Resolution Global Maps of 21st-Century Forest Cover Change. Science 2013, 342, 850-853.

88. Gorelick, N.; Hancher, M.; Dixon, M.; Ilyushchenko, S.; Thau, D.; Moore, R. Google Earth Engine: Planetaryscale geospatial analysis for everyone, Remote Sens. Environ. 2016, 202, 18-27.

89. Pekel, J.-F.; Cottam, A.; Gorelick, N.; Belward, A.S. High-resolution mapping of global surface water and its long-term changes, Nature 2016, 540, 418-422.

90. Sengupta, D.; Chen, R.; Meadows, M.E.; Choi, Y.R.; Banerjee, A.; Zilong, X. Mapping Trajectories of Coastal Land Reclamation in Nine Deltaic Megacities using Google Earth Engine. Remote Sens. 2019, 11, 2621.

91. Li, Q.; Qiu, C.; Ma, L.; Schmitt, M.; Zhu, X.X. Mapping the Land Cover of Africa at $10 \mathrm{~m}$ Resolution from Multi-Source Remote Sensing Data with Google Earth Engine. Remote Sens. 2020, 12, 602.

92. Banerjee, A.; Chen, R.E.; Meadows, M.; Singh, R.; Mal, S.; Sengupta, D. An Analysis of Long-Term Rainfall Trends and Variability in the Uttarakhand Himalaya Using Google Earth Engine. Remote Sens. 2020, 12, 709.

93. Campbell, A.; Wang, Y. Salt marsh monitoring along the Mid-Atlantic coast by Google Earth Engine enabled time series. PLOS ONE 2020, 15, e0229605.

94. Richards, D.R.; Belcher, R.N. Global Changes in Urban Vegetation Cover. Remote Sens. 2020, 12, 23.

95. Stromann, O.; Nascetti, A.; Yousif, O.; Ban, Y. Dimensionality Reduction and Feature Selection for ObjectBased Land Cover Classification based on Sentinel-1 and Sentinel-2 Time Series Using Google Earth Engine. Remote Sens. 2020, 12, 76.

96. Zhang, K.; Dong, X.; Liu, Z.; Gao, W.; Hu, Z.; Wu, G. Mapping Tidal Flats with Landsat 8 Images and Google Earth Engine: A Case Study of the China 's Eastern Coastal Zone circa 2015. Remote Sens. 2019, 11, 924.

97. Barnosky, A.D.; Hadly, E.A.; Bascompte, J.; Berlow, E.L.; Brown, J.H.; Fortelius, M.; Getz, W.M.; Harte, J.; Hastings, A.; Marquet, P.A.; et al. Approaching a state shift in Earth's biosphere. Nature 2012, 486, 52-58.

98. Urban, M.C. Accelerating extinction risk from climate change. Science 2015, 348, 571-573.

99. Wernberg, T.; Bennett, S.; Babcock, R.C.; de Bettignies, T.; Cure, K.; Depczynski, M.; Dufois, F.; Fromont, J.; Fulton, C.J.; Hovey, R.K.; et al. Climate-driven regime shift of a temperate marine ecosystem. Science 2016, 353, 169-172. 
100. Newbold, T. Future effects of climate and land-use change on terrestrial vertebrate community diversity under different scenarios. Proc. R. Soc. B 2018, 285, 20180792.

101. Warren, R.; Price, J.; Graham, E.; Forstenhaeusler, N.; VanDerWal, J. The projected effect on insects, vertebrates, and plants of limiting global warming to $1.5{ }^{\circ} \mathrm{C}$ rather than $2{ }^{\circ} \mathrm{C}$. Science 2018, 360, 791-795.

102. Trisos, C.H.; Merow, C.; Pigot, A.L. The projected timing of abrupt ecological disruption from climate change. Nature 2020, doi:10.1038/s41586-020-2189-9.

103. Thomas, C.; Gillingham, P.K. The performance of protected areas for biodiversity under climate change. Biol. J. Linn. Soc. 2015, 115, 718-730.

104. Hockings, M.; Stolton, S.; Leverington, F.; Dudley, N.; Courrau, J. Evaluating Effectiveness: A framework for Assessing Management Effectiveness of Protected Areas, 2nd ed.; IUCN: Gland, Switzerland; Cambridge, UK, 2006; p. 105.

105. Campbell, A.; Wang, Y. High Spatial Resolution Remote Sensing for Salt Marsh Mapping and Change Analysis at Fire Island National Seashore. Remote Sens. 2019, 11, 1107.

106. Wang, Y.; Ngusaru, A.; Tobey, J.; Makota, V.; Bonynge, G.; Nugranad, J.; Traber, M.; Hale, L.; Bowen, R. Remote Sensing of Mangrove Change Along the Tanzania Coast. Marine Geodesy 2003, 26(1-2): 35-48.

107. Gross, J.E.; Hansen, A.J.; Goetz, S.J.; Theobald, D.M.; Melton, F.M.; Piekielek, N.B.; Nemani, R.R. Remote Sensing for Inventory and Monitoring of U.S. National Parks. In Remote Sensing of Protected Lands; CRC Press: Boca Raton, FL, USA, 2011; pp. 29-56.

108. Nemani, R.R.; Hashimoto, H.; Votava, P.; Melton, F.; White, M.; Wang, W.; Michaelis, A.; Mutch, L.; Milesi, C.; Hiatt, S.; et al. Monitoring and forecasting ecosystem dynamics using the using the Terrestrial Observation and Prediction System (TOPS). Remote Sens. Environ. 2009, 113, 1497-1509.

109. Zhao, J.; Wang, Y.; Hashimoto, H.; Melton, F.S.; Hiatt, S.H.; Zhang, H.; Nemani, R.R. The variation of land surface phenology from 1982 to 2006 along the Appalachian Trail. IEEE Trans. Geosci. Remote Sens. 2012, 51, 2087-2095.

110. Meng, L.; Zhou, Y.; Lia, X.; Asrar, G.R.; Mao, J.; Alan, D. Wanamaker, A.D., Jr.; Wang, Y. Divergent responses of spring phenology to daytime and nighttime warming. Agric. For. Meteorol. 2020, 281, 107832

111. Mao, D.; Wang, Z.; Dua, B.; Li, L.; Tian, Y.; Jia, M.; Zeng, Y.; Song, K.; Jiang, M.; Wang, Y. National wetland mapping in China: A new product resulting from object based and hierarchical classification of Landsat 8 OLI images. Isprs J. Photogramm. Remote Sens. 2020, 164, 11-25.

112. Wang, Y. Coastal Environments: Remote Sensing. In Coastal and Marine Environments, the Handbook of Natural Resources, 2nd ed.; CRC Press: Boca Raton, FL, USA, 2020; pp. 267-276.

113. Wang, Y.; Yésou, H. Remote Sensing of Floodpath Lakes and Wetlands: A Challenging Frontier in the Monitoring of Changing Environments. Remote Sens. 2018, 10, 1955.

114. Popkin, G. U.S. government considers charging for popular earth-observing data. Nature 2018, 556, 417418.

115. Zhou, Y.; Smith, S.J.; Zhao, K.; Imhoff, M.; Thomson, A.; Bond-Lamberty, B.; Asrar, G.R.; Zhang, X.; He, C.; Elvidge, C.D. A global map of urban extent from nightlights. Environ. Res. Lett. 2015, 10, 054011.

116. Fan, L.; Zhao, J.; Wang, Y.; Ren, Z.; Zhang, H.; Guo, X. Assessment of Night-Time Lighting for Global Terrestrial Protected and Wilderness Areas. Remote Sens. 2019, 11, 2699.

117. Bei, X.; Yao, Y.; Zhang, L.; Xu, T.; Jia, K.; Zhang, X.; Shang, K.; Xu, J.; Chen, X. Long-Term Spatiotemporal Dynamics of Terrestrial Biophysical Variables in the Three-River Headwaters Region of China from Satellite and Meteorological Datasets. Remote Sens. 2019, 11, 1633.

118. Fang, L.; Crocker, E.V.; Yang, J.; Yan, Y.; Yang, Y.; Liu, Z. Competition and Burn Severity Determine PostFire Sapling Recovery in a Nationally Protected Boreal Forest of China: An Analysis from Very HighResolution Satellite Imagery. Remote Sens. 2019, 11, 603.

119. Guirado, E.; Blanco-Sacristán, J.; Rigol-Sánchez, J.P.; Alcaraz-Segura, D.; Cabello, J. A Multi-Temporal Object-Based Image Analysis to Detect Long-Lived Shrub Cover Changes in Drylands. Remote Sens. 2019, $11,2649$.

120. Chen, L.; Ren, C.; Zhang, B.; Wang, Z.; Wang, Y. Mapping Spatial Variations of Structure and Function Parameters for Forest Condition Assessment of the Changbai Mountain National Nature Reserve. Remote Sens. 2019, 11, 3004.

121. Han, Y.; Li, Z.; Huang, C.; Zhou, Y.; Zong, S.; Hao, T.; Niu, H.; Yao, H. Monitoring Droughts in the Greater Changbai Mountains Using Multiple Remote Sensing-Based Drought Indices. Remote Sens. 2020, 12, 530. 
122. Li, B.; Huang, F.; Qin, L.; Qi, H.; Sun, N. Spatio-Temporal Variations of Carbon Use Efficiency in Natural Terrestrial Ecosystems and the Relationship with Climatic Factors in the Songnen Plain, China. Remote Sens. 2019, 11, 2513.

123. Lu, C.; Ren, C.; Wang, Z.; Zhang, B.; Man, W.; Yu, H.; Gao, Y.; Liu, M. Monitoring and Assessment of Wetland Loss and Fragmentation in the Cross-Boundary Protected Area: A Case Study of Wusuli River Basin. Remote Sens. 2019, 11, 2581.

124. Shirvani, Z. A Holistic Analysis for Landslide Susceptibility Mapping Applying Geographic Object-Based Random Forest: A Comparison between Protected and Non-Protected Forests. Remote Sens. 2020, 12, 434.

125. Xu, J.; Gao, C.; Wang, Y. Extraction of Spatial and Temporal Patterns of Concentrations of Chlorophyll-a and Total Suspended Matter in Poyang Lake Using GF-1 Satellite Data. Remote Sens. 2020, 12, 622.

126. Duan, P.; Wang, Y.; Yin, P. Remote Sensing Applications in Monitoring of Protected Areas: A Bibliometric Analysis. Remote Sens. 2020, 12, 772.

127. Wang, Y. Protected Areas: Remote Sensing. In Landscape and Land Capacity, the Handbook of Natural Resources, 2nd ed.; CRC Press: Boca Raton, FL, USA, 2020; pp. 75-84.

(C) 2020 by the authors. Licensee MDPI, Basel, Switzerland. This article is an open access article distributed under the terms and conditions of the Creative Commons Attribution (CC BY) license (http://creativecommons.org/licenses/by/4.0/). 